\title{
Morphometry and Variations of Bony Ponticles of the Atlas Vertebrae (C1) in Kenyans
}

\author{
Morfometría y Variaciones de Puentes Óseos de la Vértebra Atlas (C1) en Kenianos
}

Karau Bundi, P.; Ogeng'o, J. A.; Hassanali, J. \& Odula, P. O.

\begin{abstract}
KARAU BUNDI, P.; OGENG'O, J. A.; HASSANALI, J. \& ODULA, P. O. Morphometry and variations of bony ponticles of the atlas vertebrae (C1) in Kenyans. Int. J. Morphol., 28(4):1019-1024, 2010.

SUMMARY: Atlas bridges, the bony outgrowths over the third segment of the vertebral artery are associated with compression of the artery and nerves. There are limited studies comparing morphometry of the complete atlas bridges and that of the ipsilateral transverse foramen. Bilateral and gender differences in the morphometry of the complete bridges remain relatively unexplored. One hundred and two atlas vertebrae (49 male and 53 female) obtained from the Osteology Department of the National Museums of Kenya were used for this study. The presence of complete posterior atlas bridge (retroarticular canal) and lateral bridge (supratransverse foramen) was noted. Measurements were taken for the diameters of foramina, and the ipsilateral transverse foramina and their areas calculated. Complete posterior bridges occurred in $14.6 \%$ and $13.6 \%$ on the right and left sides respectively. The lateral bridge was found in $3.9 \%$ of the cases on the right side only. The complete posterior bridges had a cross-sectional area of $23.44 \mathrm{~mm}^{2}$ on the right and $24.98 \mathrm{~mm}^{2}$ on the left side. The lateral bridges had a mean cross-sectional area of $27.30 \mathrm{~mm}^{2}$. The right and left transverse foramina had mean crosssectional area of $36.30 \mathrm{~mm}^{2}$ and $37.20 \mathrm{~mm}^{2}$ respectively, which was significantly larger than that of the ipsilateral complete and posterior bridges. The smaller dimensions of the complete atlas bridges compared to the ipsilateral transverse foramen suggest that they may predispose to vertebrobasilar insufficiency, Barre-Lieou and cervicogenic syndromes due to compression of the contents in the foramina.
\end{abstract}

KEY WORDS: Atlas bridges; Vertebral artery; Compression; Kenyans.

\section{INTRODUCTION}

Atlas bridges, also called ponticles, are bony outgrowths occurring on the atlas vertebra over the third segment of the vertebral artery, converting its groove into a sulcus, incomplete or complete foramen (Williams et al., 1995). These bridges may indicate ossification of the posterior atlanto-occipital membrane (Romanus \& Tovi, 1964), regression (Lamberty \& Zivanovic', 1973) or remnants of the proatlas (Taitz \& Nathan, 1986). The atlas bridges are a shared structure between human and non-human primates. The posterior bridge is found dorsal to the lateral mass on the posterior arch of the atlas (Le Minor \& Trost, 2004) and when complete, forms the retroarticular canal (Mitchell, 1998a, 1998b) also called a Kimmerle's variant (Kimmerle, 1930) or arcuate foramen (Von Torklus \& Gele, 1972). Lateral bridges, are less common than the posterior and may also exist as complete foramina (Mitchell, 1998a, 1998b), called the supratransverse foramina (Chevrel et al., 1965 cited by Le Minor \& Trost).
The superoinferior and anteroposterior diameters of the retroarticular canal have been shown to differ significantly (Paraskevas et al., 2005). Other workers have shown individual, gender, and side differences in the diameters of the retroarticular canal (Mitchell, 1998a, 1998b; Tubbs et al., 2007a). The cross-sectional area of the ipsilateral transverse foramen is significantly larger than that of the retroarticular canal (Tubbs et al., 2007b) increasing the risk of VA compression. The left vertebral artery has a larger diameter than the right (Thiel, 1991) suggesting that it is most predisposed to compression. On the contrary, information on the morphometry and area of the supratransverse foramen and its comparison with those of the ipsilateral transverse foramen is lacking.

Occurrence of atlas bridges especially complete and incomplete ones predispose to vertebrobasilar insufficiency, Barre-Lieou and cervicogenic syndromes especially in neck 
movements (Lamberty \& Zivanovic'). The left VA on the left side has a larger diameter than the right (Sun, 1990) while the left retroarticular canal is smaller than the right (Paraskevas et al.) making it more vulnerable than the right. Reduction in the foramen size from the transverse to the arcuate foramen causes compression of the VA (Taubbs et al., 2007b).

The aim of this study was to determine the morphometric differences between the transverse foramen of atlas vertebrae and the canals or foramina formed by the bony bridges over the vertebral artery. This might help explain the correlation between occurrence of the bony bridges or ponticles and vertebral artery entrapment.

\section{MATERIAL AND METHOD}

After due ethical approval one hundred and two atlas vertebrae obtained from the Osteology department of the National Museums of Kenya's were studied. Broken and incomplete atlases and those without gender labels were excluded. The atlas bridges were identified following the criteria used by Chevrel et al. (cited by Le Minor \& Trost) and Mitchell (1998a, 1998b). Posterior bridge is a bony outgrowth over the groove for the vertebral artery located dorsal to the lateral mass on the posterior arch of the atlas and the canal formed, when complete is called the retroarticular canal. Lateral bridge is a lateral outgrowth of bone from the superior articular facet or lateral mass to the posterior root of the transverse process of the atlas and complete, the foramen formed is termed the supratransverse foramen.

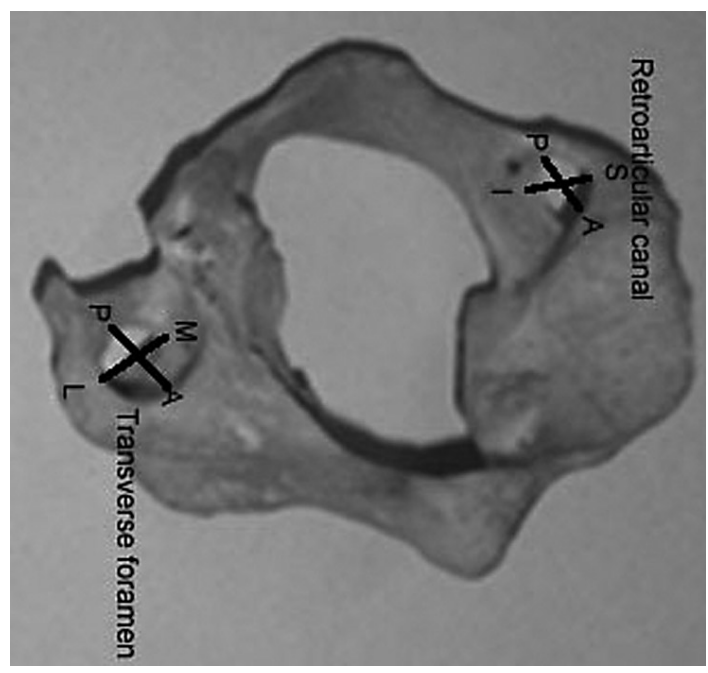

Fig. 1. The dimensions taken for the retroarticular canal (SI; Supero-inferior and AP; anteroposterior diameters) and the transverse foramen (ML; mediolateral diameter)
For the retroarticular canal, superoinferior and anteroposterior diameters were measured using Namutan digital calipers with a precision of $+/-0.05 \mathrm{~mm}$. Superoinferior diameter was taken from the floor of the groove to the inner part of the overlying bony strut, whereas anteroposterior was taken from the posterior part of the groove on the posterior arch to the root of the superior articulating surface. In the case of the supratransverse foramen, the superoinferior diameter was measured from the floor of the lateral mass to the bony strut from the superior articulating facet. Mediolateral diameter was taken as the distance from the bony bridge between the superior articulating facet and lateral part of transverse process and root of the superior articulating facet. In all cases, the anteroposterior and mediolateral diameters of the ipsilateral transverse foramina were measured. Figure 1 illustrates the measurements.

The cross-sectional area of the retroarticular canal, supratransverse foramen and ipsilateral transverse foramina were calculated using the formula for an ellipse:

Area $=$ pi $(\mathrm{D} 1 / 2 \times \mathrm{D} 2 / 2)$

Where D1= horizontal length of the foramen, D2 = vertical length of the foramen and $\mathrm{Pi}=3.14$

The data was analysed using the Statistical Package for Social Sciences (SPSS) software version 15.0. The mean, standard deviation and range for each of the measurements were calculated for all measurements and calculations.

\section{RESULTS}

The retroarticular canal was present in 29 sides out of 204 sides $(14.2 \%$ ), with an insignificant difference between the right and left sides. The supratransverse foramen was found in four atlases on the right side only.

The mean anteroposterior diameter of the right retroarticular canal was $6.29 \mathrm{~mm}$ with $6.06 \mathrm{~mm}$ in males and $7.27 \mathrm{~mm}$ in females. The superoinferior diameter was $5.11 \mathrm{~mm}$ with $5.26 \mathrm{~mm}$ in males and $5.63 \mathrm{~mm}$ in females. The superoinferior diameter was significantly larger in females than males $(p=0.043)$. On the right side, the anteroposterior diameter was significantly larger than the superoinferior $(\mathrm{p}=0.001)$.

On the left side, the mean anteroposterior diameter was $6.00 \mathrm{~mm}$ with males having $5.25 \mathrm{~mm}$ and females $6.30 \mathrm{~mm}$. The mean superoinferior diameter was $5.16 \mathrm{~mm}$ with males at $5.90 \mathrm{~mm}$ and females $4.86 \mathrm{~mm}$. There were no 
significant differences in the diameters between males and females. As opposed to the right side, there was no statistically significant difference between the superoinferior and anteroposterior diameters.

The supratransverse foramen superoinferior diameter was $5.05 \mathrm{~mm}$, with males having $5.70 \mathrm{~mm}$ and females $4.85 \mathrm{~mm}$. The mean mediolateral diameter was $5.45 \mathrm{~mm}$, with males having $5.38 \mathrm{~mm}$ and females $5.53 \mathrm{~mm}$. There were no statistically significant differences between the two diameters $(\mathrm{p}=0.957)$ or with gender.

On the right side, the mean anteroposterior diameter of the transverse foramen was $7.05 \mathrm{~mm}(7.57 \mathrm{~mm}$ for males and $6.73 \mathrm{~mm}$ for females). The mean mediolateral diameter or horizontal diameter was $6.50 \mathrm{~mm}(6.63 \mathrm{~mm}$ in males and $6.41 \mathrm{~mm}$ in females). There, gender difference in the anteroposterior diameter was significant at $\mathrm{p}=0.01$, while that of the mediolateral diameter was insignificant at $p=0.495$. There was significant difference between the mediolateral and anteroposterior diameters $(p=0.004)$.

The mean anteroposterior diameter on the left transverse foramen was $7.04 \mathrm{~mm}(7.47 \mathrm{~mm}$ in males and $6.78 \mathrm{~mm}$ in females). The mean mediolateral diameter was $6.76 \mathrm{~mm}(6.71 \mathrm{~mm}$ in males and $6.79 \mathrm{~mm}$ in females). As opposed to the right side, there was no statistically significant difference between the two parameters.

The mean area of the retroarticular canal was $23.44 \mathrm{~mm}^{2}$ and $24.98 \mathrm{~mm}^{2}$ for the right and the left respectively. Although females had larger cross-sectional areas than males, it was not statistically significant. There was no statistically significant difference in the area of the left and right sides. The supratransverse foramen had a crosssectional area of $27.30 \mathrm{~mm}^{2}$.

The mean area of the right transverse foramina was $36.30 \mathrm{~mm}^{2}$ while the mean area for the left was $37.20 \mathrm{~mm}^{2}$. There was no statistically significant gender or bilateral asymmetry. Table I summarizes the findings on the areas.

The mean area of the transverse foramina was invariably larger than that of the retroarticular canals and supratransverse foramina. On the left side, the statistical significance was 0.03 while on the right side it was 0.05 .

\section{DISCUSSION}

The present study has identified a retroarticular canal in $14.2 \%$ of the Kenyan population derived mainly from Central Kenya. This is within the range described by previous authors in different populations (Mitchell, 1998a, 1998b; Sun). Complete lateral bridges, forming supratransverse foramina were found in $3.9 \%$ of the cases in the present study, all on the right side. Out of the 4 complete lateral bridges on the right side, 3 were from females and 1 male. The findings of the present study support those of previous research that complete lateral bridges are less common compared to the posterior bridges (Mitchell, 1998a, 1998b; Taitz \& Nathan).

For the retroarticular canal, the mean anteroposterior diameter was $6.29 \mathrm{~mm}$ on the right and $6.00 \mathrm{~mm}$ on the left, with females having larger diameters than males. The mean superoinferior diameter was $5.11 \mathrm{~mm}$ on the right and $5.16 \mathrm{~mm}$ on the left. These measurements concur with those of the previous research as shown in Table II.

Our results support those of previous workers (Mitchell, 1998a, 1998b; Paraskevas et al.), that the anteroposterior diameter is significantly larger than the superoinferior in the retroarticular canal. They also concur that there are no significant bilateral or gender differences. It is therefore possible that the vertebral artery is compressed superoinferiorly (Mitchell, 1998a, 1998b). The left vertebral artery has been found to be larger than the right (Thiel). This would mean that it is more liable to compression, although the presence of more bridges on the right side, and the small diameters in the present findings suggest that the right vertebral artery is more predisposed to compression.

The mean superoinferior diameter of the supratransverse foramen of the lateral bridge was $5.05 \mathrm{~mm}$, with males having $5.70 \mathrm{~mm}$ and females $4.85 \mathrm{~mm}$. The mean mediolateral diameter was $5.45 \mathrm{~mm}$, with males having

Table I. The areas of retroarticular canals, supratransverse and ipsilateral atlas transverse foramina with sex.

\begin{tabular}{lcccccr}
\hline Sex & \multicolumn{2}{c}{ Retroarticular canal } & \multicolumn{2}{c}{ Supratransverse foramen } & \multicolumn{2}{c}{ Transverse foramen } \\
\hline \multirow{3}{*}{ Male } & Right & Left & Right & Left & Right & Left \\
\cline { 2 - 6 } Female & 23.10 & 24.45 & 27.30 & & 39.78 & 38.59 \\
Mean areas & 25.57 & 24.50 & 27.30 & & 34.06 & 36.13 \\
\hline
\end{tabular}


$5.38 \mathrm{~mm}$ and females $5.53 \mathrm{~mm}$. There are no significant differences between the two diameters or with gender. The lateral bridge may form an additional foramen for the vertebral artery (Mitchell, 1998a, 1998b). Relatively little attention has previously been paid on dimensions of the complete lateral bridges, as evidenced by paucity of data in previous literature. These are however important, in calculating the cross-sectional area of the foramen and knowing the direction of compression of the artery. It is therefore possible that the most likely direction of compression of the vertebral artery is superoinferior, like in the retroarticular canal.

The anteroposterior diameter of the transverse foramen was significantly larger in males than females on the right side. This is at variance with other findings that the ventrodorsal and mediolateral dimensions of the foramina transversaria did not differ significantly (Hasan et al., 2001). Taubbs et al. (2007b) calculated the area of the transverse foramina although he did not give the dimensions he used. The vertebral artery covers about two thirds of the minimal diameter and more than half of the maximal diameter of the transverse foramen (Abd el-Bary et al., 1995). In the present study, the anteroposterior diameter on the right side was significantly larger than the mediolateral diameter. This may be attributed to osteophytes that narrow the mediolateral diameter and may predispose to compression of the vertebral artery and dissection (Cagnie et al., 2005).

In the present study, the mean area of the retroarticular canal was found to be $23.44 \mathrm{~mm}^{2}$ and $24.98 \mathrm{~mm}^{2}$ on the right and left sides respectively. Although females had larger crosssectional area than males, it was not statistically significant. Our results on the area of the retroarticular canal are significantly higher than those by previous authors. It was found to be $14.2 \mathrm{~mm}^{2}$ among Iranians (Taubbs et al., 2007a) and $12.5 \mathrm{~mm}^{2}$ among Americans (Taubbs et al., 2007b). Perhaps the difference might be in part due to method disparity and ethnic variations. We used digital vernier calipers, while the previous workers did not specify the instruments they used. Further studies need to be done locally to know the size of the vertebral artery hence its likelihood of compression. The supratransverse foramen had a crosssectional area of $27.30 \mathrm{~mm}^{2}$. There is paucity of information on the area of supratransverse foramina.

The mean cross-sectional area of the right transverse foramina was $36.30 \mathrm{~mm}^{2}$ while that of the left was $37.20 \mathrm{~mm}^{2}$, with no gender or side differences. This is significantly higher than that measured among Iranians (Taubbs et al., 2007a) and Americans (Taubbs et al., 2007b). More notable is the fact that areas of the retroarticular canals and supratransverse foramina are significantly smaller than the area of the ipsilateral transverse foramina on both sides. This concurs with the findings of previous research (Taubbs et al., 2007a, 2007b). The difference in the dimensions of the complete atlas bridges and transverse foramina means that the space for vertebral artery to pass through is reduced, and this may compromise blood flow in the vessel (Mitchell, 1998a, 1998b). Our study supports previous assertions that presence of complete atlas bridges can lead to compression of the vertebral artery in the absence of arterial disease, and may be an aggravating factor in case of disease (Mitchell, 1998a, 1998b; Paraskevas et al.). This compression becomes evidently symptomatic in extreme manipulations of the neck (Limousin, 1980). The prevalence of bony ponticles on the path of the vertebral artery is high compared to the prevalence of compression syndromes. It is possible that the third segment of the VA may be a reserve length to allow for neck rotation without injury or compression to the artery. Presence of these ponticles may limit this reserve length, predisposing to entrapment of the artery.

In conclusion, the prevalence of bony ponticles in the atlas among Kenyans are comparable to that in other populations. This is among the first studies providing information on the morphometry of complete atlas bridges and ipsilateral transverse foramina and their implications. The observation that the atlas bridge foramina are smaller than ipsilateral transverse foramina suggests that they are

Table II. Comparison of the diameters of retroarticular canal in different populations.

\begin{tabular}{|c|c|c|c|c|}
\hline \multirow[t]{2}{*}{ Author and population } & \multicolumn{2}{|c|}{ Retroarticular canal } & \multicolumn{2}{|c|}{ Supratransverse foramen } \\
\hline & Right & Left & Right & Left \\
\hline Pyo \& Lowman, 1959. (American whites). & \multicolumn{2}{|c|}{$8.5 \mathrm{~mm}^{* * * *}$} & ------ & ------ \\
\hline Mitchell, 1998a (mixed South Africans). & 6.4 & 6.6 & 5.3 & 5.1 \\
\hline Unur et al., 2004 (Turkish). & \multicolumn{2}{|c|}{$8.1 \mathrm{~mm}^{* * * *}$} & \multicolumn{2}{|c|}{$5.7 \mathrm{~mm} * * * *$} \\
\hline Paraskevas et al., 2005 (Northern Greeks). & 6.4 & 6.7 & 5.4 & 5.4 \\
\hline Present study & 6.29 & 6.00 & 5.11 & 5.16 \\
\hline
\end{tabular}

***** The sides are not specified. 
an important cause of vertebral artery compression. The relatively high prevalence of the bony ponticles of the atlas compared to vertebral artery compression syndromes suggests multifactorial aetiology for the syndromes.
ACKNOWLEDGEMENT. We convey our gratitude to the Mr. Ogeto of the department of osteology at the National Museums of Kenya for allowing us access to the specimens.

KARAU BUNDI, P.; OGENG'O, J. A.; HASSANALI, J. \& ODULA, P. O. Morfometría y variaciones de puentes óseos de la vértebra atlas (C1) en Kenianos. Int. J. Morphol., 28(4):1019-1024, 2010.

RESUMEN: Puentes del atlas, sobrecrecimientos óseos en el tercer segmento de la arteria vertebral se asocian con la compresión de la arteria y los nervios. Hay pocos estudios que comparan la morfometría de los puentes completos del atlas y el foramen transversal ipsilateral. Diferencias bilaterales y de género en la morfometría de los puentes completos permanecen relativamente inexplorados. Ciento dos vértebras atlas (49 hombres y 53 mujeres) obtenidos del Departamento de Osteología de los Museos Nacionales de Kenya se utilizaron para este estudio. Fueron identificados la presencia de puentes completos posteriores del atlas (canal retroarticular) y puentes laterales (foramen supratransverso). Se realizaron las mediciones de los diámetros del foramen y los forámenes transversos ipsilaterales, y se calcularon sus áreas. Puentes completos posteriores se observaron en el 14,6\% y 13,6\% de los lados derecho e izquierdo, respectivamente. El puente lateral se encontró en el 3,9\% de los casos en el lado derecho solamente. Los puentes completos posteriores tuvieron un área transversal de $23,44 \mathrm{~mm}^{2}$ en el lado derecho y $24,98 \mathrm{~mm}^{2}$ en el lado izquierdo. Los puentes laterales tuvieron un área media de sección transversal de $27,30 \mathrm{~mm}^{2}$. En los lados derecho e izquierdo se encontrron forámenes transversos con un área promedio de sección transversal de $36,30 \mathrm{~mm}^{2}$ y $37,20 \mathrm{~mm}^{2}$ respectivamente, lo que fue significativamente mayor que el de los puentes completos ipsilaterales y posteriores. Las dimensiones más pequeñas de los puentes atlas completos en comparación con los forámenes transversos ipsilaterales sugieren que pueden predisponer a la insuficiencia vertebrobasilar, síndromes de Barre-Lieou y cervical debido a la compresión de los contenidos en los forámenes.

PALABRAS CLAVE: Puentes del Atlas; Arteria vertebral; Compresión; Kenianos.

\section{REFERENCES}

Abd el-Bary, T. H.; Dujovny, M. \& Ausman, J. I. Microsurgical anatomy of the atlantal part of the vertebral artery. Surg. Neurol., 44(4):392-401, 1995.

Cagnie, B.; Barbaix, E.; Vinck, E.; D'Herde, K. \& Cambier, D. Extrinsic risk factors for compromised blood flow in the vertebral artery: anatomical observations of the transverse foramina from C3 to C7. Surg. Radiol. Anat., 27(4):312-6, 2005.

Hasan, M.; Shukla, S.; Siddiqui, M. S. \& Singh, D. Posterolateral tunnels and ponticuli in human atlas vertebra. J. Anat., 199:339-43, 2001.

Kimmerle, A. Ponticulus posticus. Rotogenprax., 2:479-83, 1930.

Lamberty, B. G. \& Zivanovic', S. The retro-articular vertebral artery ring of the atlas and its significance. Acta Anat., 85:113-22, 1973.

Le Minor, J. M. \& Trost, O. Bony ponticles of the atlas (C1) over the groove for the vertebral artery in humans and primates: Polymorphism and evolutionary trends. Am. J. Phys. Anthropol., 125:16-29, 2004.
Limousin, C. A. Foramen arcuale and syndrome of BarreLieou. Int. Orthop., 4:19-23, 1980.

Mitchell, J. The incidence and dimensions of the retroarticular canal of the atlas vertebra. Acta Anat., 163:113-20, 1998a.

Mitchell, J. The incidence of the lateral bridge of the atlas vertebra. J. Anat., 193:283-5, 1998 b.

Paraskevas, G.; Papaziogas, B.; Tsonidis, C. \& Kapetanos, G. Gross morphology of the bridges over the vertebral artery groove on the atlas. Surg. Radiol. Anat., 27:12936, 2005.

Pyo, J. \& Lowman, R. M. The ponticulus posticus of the first cervical vertebra. Radiology, 72:850-4, 1959.

Romanus, T. \& Tovi, A. A variation of the atlas. Roentgenolgic incidence of a bridge over the groove on the atlas for the vertebral artery. Acta Radiol. Diagn. (Stockh), 2:289-97, 1964.

Sun, J. Y. Foramen arcuale and vertigo. Zhonghua Wai Ke Za Zhi, 28:592-4, 636-7, 1990. 
KARAU BUNDI, P.; OGENG'O, J. A.; HASSANALI, J. \& ODULA, P. O. Morphometry and variations of bony ponticles of the atlas vertebrae (C1) in Kenyans. Int. J. Morphol., 28(4):1019-1024, 2010.

Taitz, C. \& Nathan, H. Some observations on the posterior and lateral bridge of the atlas. Acta Anat., 127:212-7, 1986.

Thiel, H. Gross morphology and pathoanatomy of the vertebral arteries. J. Manipulative Physiol. Ther, 14:13341, 1991.

Tubbs, R. S.; Shoja, M. M.; Shokouhi, G.; Farahani, R. M.; Loukas, M. \& Oakes, W. J. Simultaneous lateral and posterior ponticles resulting in the formation of a vertebral artery tunnel of the atlas: case report and review of the literature. Folia Neuropathol., 45:43-6, 2007a.

Tubbs, R. S.; Johnson, P. C.; Shoja, M. M.; Loukas, M. \& Oakes, W. J. Foramen arcuale: anatomical study and review of the literature. J. Neurosurg. Spine, 6:31-4, $2007 b$.

Unur, E.; Erdogan, N.; Ülger, H.; Ekinci, N. \& Öztürk, O. Radiographic incidence of complete arcuate foramen in Turkish population. Erciyes Med. J., 26:50-4, 2004.

Von Torklus, D. \& Gele, W. The upper cervical spine. New York, Grune and Stratton, 1972. pp.28-30.

Williams, P. L.; Banister, L. H.; Berry, M. M.; Collins, P.; Dyson, M.; Dussek, J. E. \& Fergusson, M. W. J. Gray's Anatomy. $38^{\text {th }}$ Edition. Skeletal system. London, Churchill Livingstone, 1995. pp.518-9.

\section{Correspondence to: \\ Karau Bundi, P. \\ Department of Human Anatomy \\ University of Nairobi \\ P.O.BOX 30197-00100, Nairobi \\ KENYA}

Email: pbkarau@gmail.com

Received: 16-06-2010

Accepted: 16-09-2010 